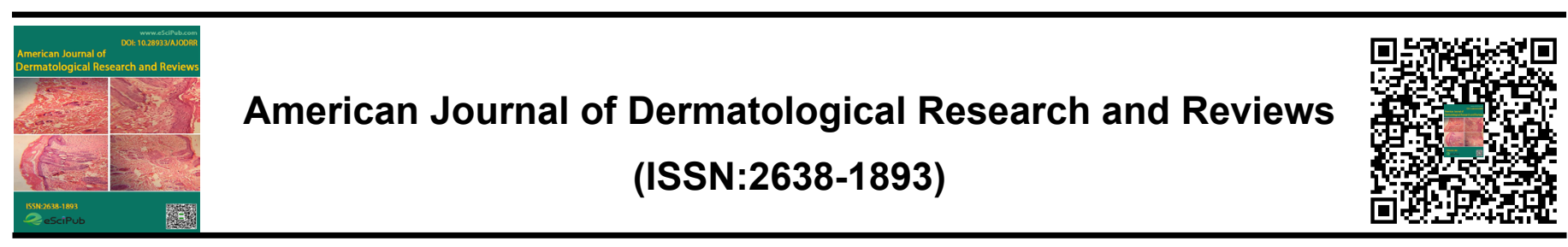

\title{
Follicular Dermatoses in Iraqi Patients (Clinical and Histopathological
}

\section{Evaluation)}

\section{${ }^{1}$ Professor Adil A. Noaimi MD, DDV, FICMS, ${ }^{2}$ Dr. Rusul A. Flayih MD.}

${ }^{1}$ Department of Dermatology, College of Medicine, University of Baghdad. Iraqi and Arab Board for Dermatology and Venereology, Baghdad Teaching Hospital, Medical City, Baghdad, Iraq; ${ }^{2}$ Center of Dermatology; Baghdad Teaching Hospital; Medical City,Baghdad,Iraq

\section{ABSTRACT}

Background: Follicular dermatoses are skin diseases that involved the hair follicle either early or during the course of the disease. Objective: To collect a number of dermatoses where there is follicular involvement, to be studied and analysed in order to reach a conclusion that hair follicles are the most important target area in the pathogenesis of these dermatoses. Patients and Methods: This is a descriptive, clinical and histopathological study that was carried out at the Centre of Dermatology and Venereology, Baghdad Teaching Hospital, Medical City, Baghdad, Iraq during the period from December 2017 to August 2019. Forty patients with follicular dermatoses were included and all socio- demographic data related to the disease was obtained from each patient, in addition to clinical examination was performed for each patient. Lesional biopsies were done for 20 patients, for histopathological examination by Haematoxylin and Eosin (H\&E). Results: The mean age \pm SD was $30.2 \pm 16.96$ years, 25 patients were males and 15 patients were females, the clinical diagnosis of follicular diseases was established for all skin diseases included in the present work. The histopathological findings of lesional biopsies were mainly: perifollicular lymphocytes, follicular invasion and degeneration, follicular plugging, fibrous tract remnant, perifollicular melanophages and hair follicle cyst.

Conclusion: The result of the present study does encourage us to suggest that almost all skin diseases included in this study start initially on the hair follicle and then spread to involve the adjacent epidermis.

Keywords: Follicular dermatoses, Hair follicle.
*Correspondence to Author:

Professor Adil A. Noaimi

Department of Dermatology, College of Medicine, University of Baghdad. Iraqi and Arab Board for Dermatology and Venereology, Baghdad Teaching Hospital, Medical City, Medical Collection Office, P.O. Box 61080 Postal Code 12114,Baghdad, Iraq

How to cite this article:

Adil A. Noaimi, Rusul A. Flayih. Follicular Dermatoses in Iraqi Patients (Clinical and Histopathological Evaluation). American Journal of Dermatological Research and Reviews, 2020, 3:28

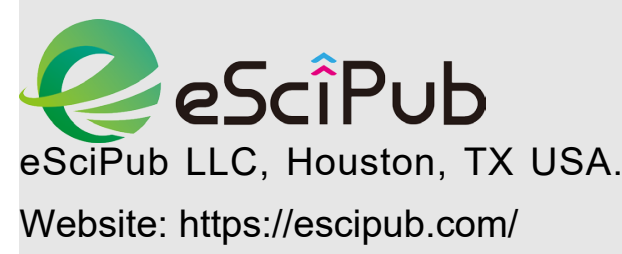




\section{Introduction}

Follicular dermatoses is well recognized dermatological problem. What have been published in medical literature including well defined entities like acne vulgaris, keratosis pilaris, and lichen planus. (1-3) But, on daily clinical practice we have been across numerous skin diseases might presented early or during course of the disease with follicular lesions. These lesions might be seen by naked eye as follicular papules, pustules, nodules and plaques or by microscope. This observation raised a biggest question is that why the follicular lesions are commonly encountered in daily dermatological practice, probably because the follicles are an important skin appendages that have a distinctive anatomy and morphology (4) and immunity (5), in addition to their specific blood supply, all of these factors might lead to more intense inflammatory reaction in these structures, like in psoriasis, seborrhoec dermatitis and many other diseases. $(6,7)$.

Therefore the present work was arranged in order to collect a number of dermatoses where there is follicular involvement to be studied and analysed in order to reach a conclusion that hair follicles are the most important target area in the pathogenesis of these dermatoses.

\section{Patients and Methods}

This is a descriptive clinical and histopathological study that was done at the Centre of Dermatology and Venereology, Baghdad Teaching Hospital, Medical City, Baghdad, Iraq during the period from December 2017 to August 2019.

Formal consent was taken from each patient and/or their parents after full explanation of the goal and the nature of the study. The ethical approval was given by the Scientific Committee of the Scientific Council of Dermatology and Venereology-Iraqi Board for Medical Specializations.

Forty patients were enrolled with clinically follicular diseases. The demographic features: age, gender, occupation, marital status, age of the disease at presentation, associated symptoms, onset, family history of the same disease, past medical, surgical and drug history. The physical examination was performed for each case regarding: sites involved morphology, and any associated features. Medical photographic documentation of the lesional sites was done by using Samsung Galaxy ${ }^{\circledR}$ S6 12megapixel digital camera in the same place and illumination. Clinical examination was done for each patient and photographing was taking for the most representative skin lesion at variable sites. Skin biopsy was done for twenty patients only. Four-millimetre punch biopsies were taken from the most representative skin lesion at variable sites, the specimens then saved in the formalin and send to the laboratory to be submitted for vertical sectioning and Haematoxylin-Eosin staining. Data were statistically described in term of range, mean, standard deviation, frequencies and relative frequencies by using SPSS $\AA_{\text {Software. }}$

\section{Results}

Forty patient, were 25 patients were males and 15 patients were females. Male to female ratio 1.6:1, their age ranged from 1-80 years with a mean \pm SD $30.2 \pm 16.96$ years. The lesional biopsy were taken for twenty patient $9(45 \%)$ male and $11(55 \%)$ female, while the remaining twenty patient were diagnosed clinically $16(80 \%)$ males and 4 (20\%) females. The sociodemographic features demonstrated in (Table-1).

Clinical results: All patients were examined clinically, and found to have follicular involvement in different body sites in a form of papules, pustules, nodules and plaques. Associated signs in the form of scales, erythema, crustation, patchy hair loss, atrophy, scarring, and dyspigmentation of skin have also been documented. The clinical diagnosis of diseases was psoriasis, atopic dermatitis and other diseases. The clinical diagnosis of all diseases in this study was elucidated by (Table-2), (Figures: 1-4). 
Histopathological findings: Twenty patients 2 (10\%), basal liquefaction in 2 (10\%), were examined using light microscope of H\&E periappeandigeal infiltrations with lymphocytes stained sections. The follicular findings are apart from hair follicle in $2(10 \%)$, solar elastosis shown in (Table-3). The following associated in 1 (5\%), epidermal atrophy in one (5\%), pathological features were also seen: regular parakeratosis in one $(5 \%)$, hyperkeratosis in one and irregular acanthosis in $5(25 \%)$, superficial (5\%), dyskeratosis in one $(5 \%)$, churg spire in and deep perivascular lymphocyte infiltrations in one (5\%), corpse round and grain in one $4(20 \%)$, pseudoepitheliomatous hyperplasia in $(5 \%)$ (Figures: $5-8)$.

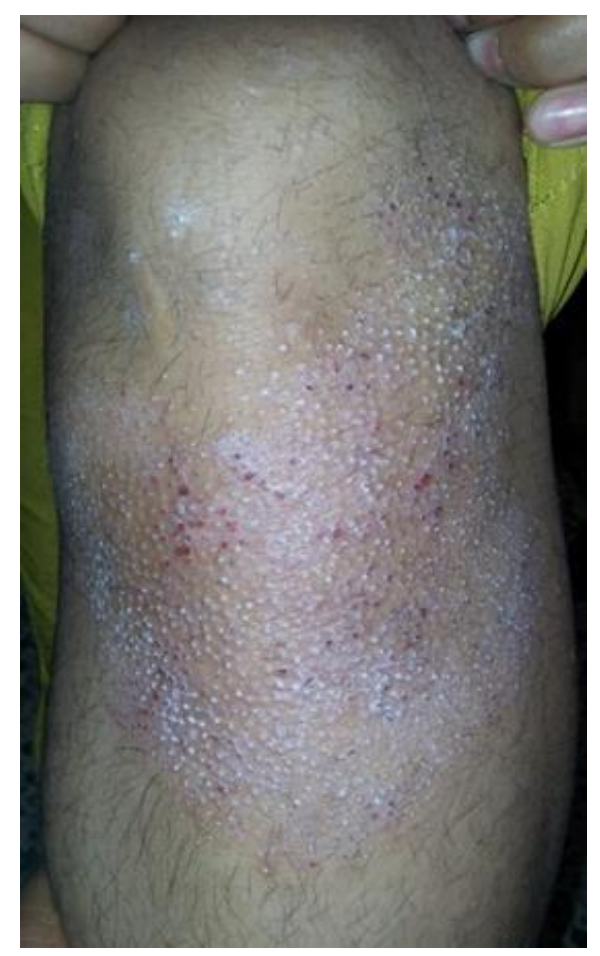

Figure-1:Thirty years old male showing erythematous scaly follicular papules in psoriatic plaques.

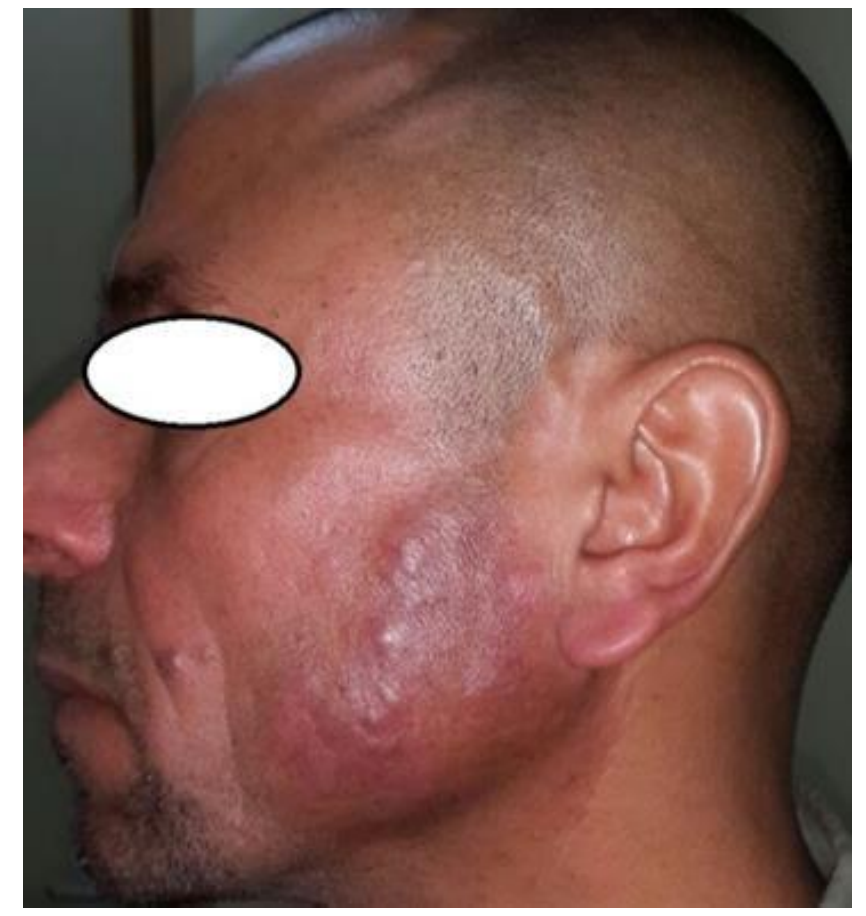

Figure-2:Thirty three years old male showing folliculotropic mycosis fungoides. 


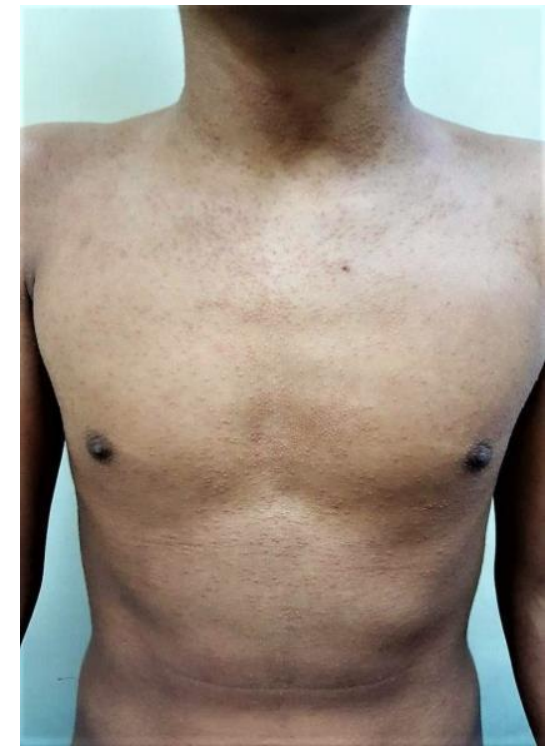

Figure -3: Seventeen years old male with Lichen Spinulosus.

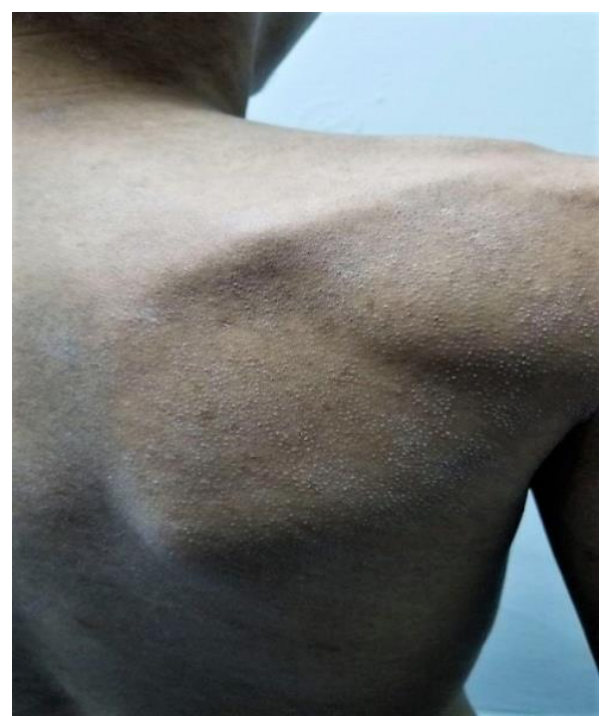

Figure-4:Twenty nine years old male with Graft Versus Host Disease.

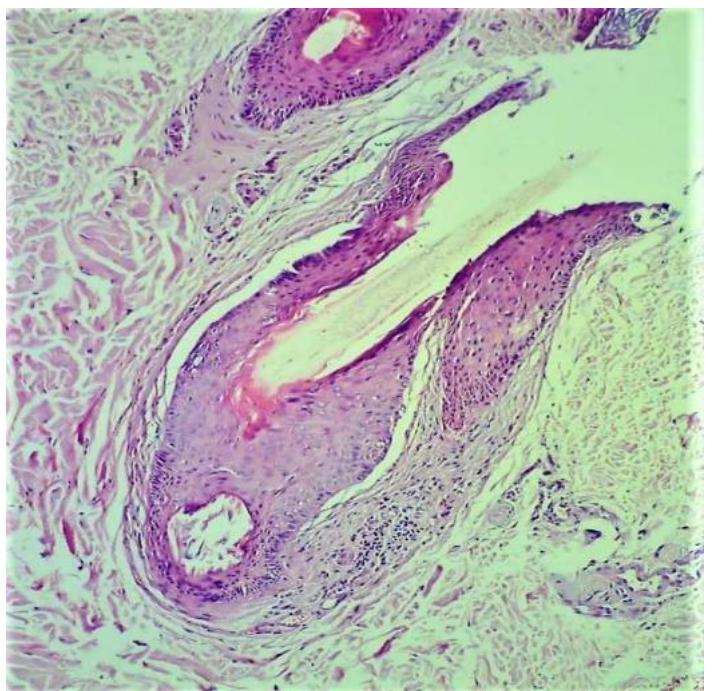

Figure-5: Microscopic view of patient with Darier's disease showing early damage of hair follicle, $X \mathbf{4 0 0}$. 


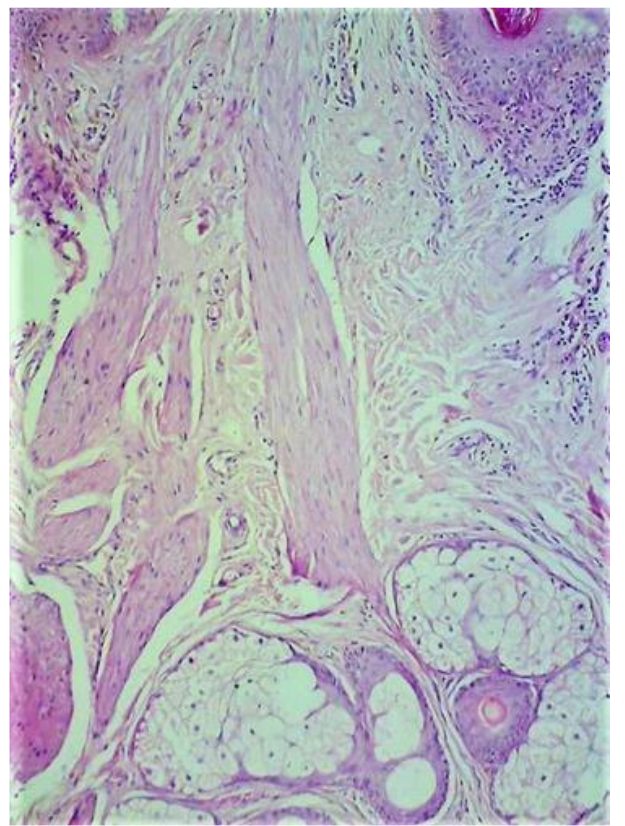

Figure-6: Microscopic view showing fibrous tract remnant in patient with lichen planus pilaris, $\mathrm{X} 400$.

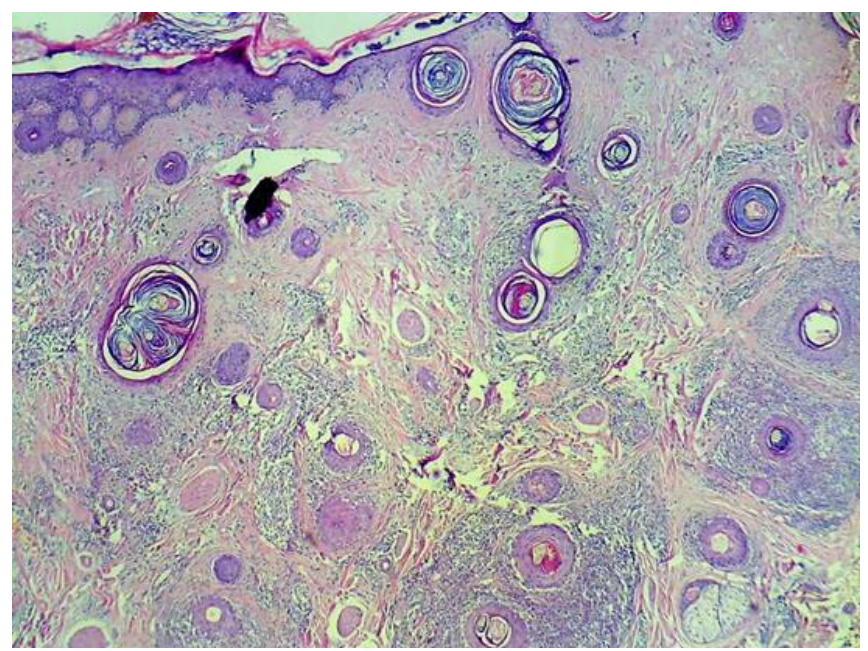

Figure-7:H\&E section of patient with DLE showing follicular plugging, perifollicular lymphocyte and destruction of the hair follicle, X100.

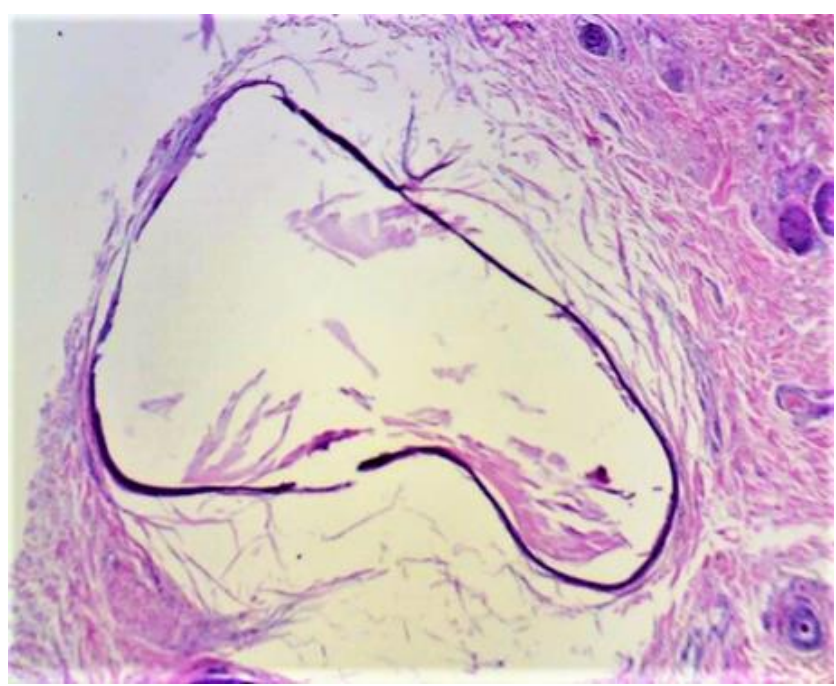

Figure-8: H\&E section of patient with villous hair cyst showing follicular cyst, X100 
Adil A. Noaimi et al., AJODRR, 2020 3:28

Table -1: Demographic data of all patients.

\begin{tabular}{|l|l|l|}
\hline Demographic data & number & Percentage \\
\hline Total number of patients & 40 & $100 \%$ \\
\hline Male patients & 25 & $62.5 \%$ \\
\hline Female patients & 15 & $37.5 \%$ \\
\hline Age range & $1-80$ years & $*$ \\
\hline Mean \pm standard deviation of age & $30.2 \pm 16.96$ years & $*$ \\
\hline Number of biopsies & 20 & $50 \%$ \\
\hline Symptomatic presentations & 33 & $82.5 \%$ \\
\hline Asymptomatic presentations & 7 & $17.5 \%$ \\
\hline
\end{tabular}

Table -2: Showing clinical diagnosis of the follicular diseases.

\begin{tabular}{|c|c|c|c|c|}
\hline $\begin{array}{l}\text { Clinical Diagnosis } \\
\text { Diseases }\end{array}$ & of & Number of Patients & Total No. & percentage \\
\hline \multicolumn{3}{|l|}{ Males } & \multicolumn{2}{|l|}{ Females } \\
\hline Psoriasis & 4 & 1 & 5 & $12.5 \%$ \\
\hline Lichen Planopilaris & 2 & 1 & 3 & $7.5 \%$ \\
\hline $\begin{array}{l}\text { Discoid Lupus } \\
\text { Erythematous }\end{array}$ & 2 & 3 & 5 & $12.5 \%$ \\
\hline Acniform & 1 & 2 & 3 & $7.5 \%$ \\
\hline Keratosis Pilaris & 1 & 2 & 3 & $7.5 \%$ \\
\hline Prurigo Nodularis & 1 & 2 & 3 & $7.5 \%$ \\
\hline Seborrhic Dermatitis & 2 & 0 & 2 & $5 \%$ \\
\hline $\begin{array}{l}\text { Folliculotropic } \\
\text { Mycosis Fungodis }\end{array}$ & 1 & 1 & 2 & $5 \%$ \\
\hline Tinea & 1 & 1 & 2 & $5 \%$ \\
\hline $\begin{array}{l}\text { Graft Versus Host } \\
\text { Disease }\end{array}$ & 2 & 0 & 2 & $5 \%$ \\
\hline $\begin{array}{l}\text { Hidradenitis } \\
\text { Suppurativa }\end{array}$ & 2 & 0 & 2 & $5 \%$ \\
\hline Lichen Spinolosis & 2 & 0 & 2 & $5 \%$ \\
\hline $\begin{array}{ll}\text { Lichen } & \text { Simplex } \\
\text { Chronicus } & \end{array}$ & 2 & 1 & 3 & $7.5 \%$ \\
\hline $\begin{array}{l}\text { Perforating } \\
\text { Folliculitis }\end{array}$ & 0 & 1 & 1 & $2.5 \%$ \\
\hline Pityriasis Versicolour & 1 & 0 & 1 & $2.5 \%$ \\
\hline Vellous Hair Cyst & 1 & 0 & 1 & $2.5 \%$ \\
\hline Total & 25 & 15 & 40 & $100 \%$ \\
\hline
\end{tabular}


Table -3: Showing histopathological findings.

\begin{tabular}{|l|l|l|}
\hline Histopathological finding & Number & Percentage \\
\hline Perifollicular lymphocytes infiltration & 20 & $100 \%$ \\
\hline $\begin{array}{l}\text { follicular invasion and degeneration } \\
\text { by lymphocytes }\end{array}$ & 8 & $40 \%$ \\
\hline Follicular plugging & 5 & $25 \%$ \\
\hline $\begin{array}{l}\text { Hair follicules damage with fibrous } \\
\text { tract remnant }\end{array}$ & 5 & $25 \%$ \\
\hline Perifollicular melanophages & 3 & $15 \%$ \\
\hline Hair follicule cyst & 1 & $5 \%$ \\
\hline
\end{tabular}

\section{Discussion}

To the best of our knowledge, this is the first study to classify follicular dermatoses in such details in Iraq and even in the world, showing clinical and histopathological evaluation in such details and will be a very good teaching subject for most dermatologists. There are numerous skin diseases with established clinical and histopathological picture, but still many dermatologists are unaware that the main target in these diseases is the hair follicles. So the target of this study is to collect and categorise of various skin diseases where the hair follicle is the cornerstone of the pathological process or the hair follicle is involved during the course of the disease process like in acne, folliculitis, lichen planopilaris and other diseases. (1-3). The hair follicles are important skin appendages, covering almost whole body except few areas like lips, palm and sole, of which its outer root sheath cells in the infundibulum formed by downward extension of epidermis which will be histologically similar to keratinocytes of epidermis and forms a granular layer during keratinazation (8); this means that the pathological changes that occur in outer root sheath might be identical to the changes that affect the keratinocytes.

In the isthmus, outer root sheath cells keratinized in a trichilemmal fashion, lacking granular layer and normally express an array of keratins, adhesion molecules, cytokines, and growth factor receptors that are distinct from those expressed by epidermal cells. They migrate out of the follicle and regenerate the epidermis after injury or loss. (9)

The immunology of hair is very amazing and complicated. The hair follicle represents an immune privileged (IP) site, which is defined basically as a location in the body where foreign tissue grafts can survive for longer periods of time without immune rejection. This specialized immune environment of $I P$ is required to prevent destructive immune reactions in critical regions. Other immune privileged sites include the anterior chamber of the eye, testis, brain and placenta. Hair follicle IP has a unique characteristic of recurring in a cyclic pattern. Until recently, the IP of the hair follicle is considered to be restricted to the matrix region during the anagen phase. However, evidence has accumulated that the IP of the hair follicle extends to the bulge region and is present at this site during the entire hair cycle. Since the bulge represents the hair follicle stem cell niche, sustained IP in this region may be essential for the survival of the follicle. (5) Hair follicle IP occurs during anagen (10). The hair follicle IP is maintained by several factors: Down regulation of MHC class I expression in the proximal ORS and matrix cells, local production of potent immune-suppressants like TGF- $\beta 1, \mathrm{IL}-10$ and $\alpha$ $\mathrm{MSH}$, functional deterioration of antigen presenting cells, absence of lymphatic, establishment of extracellular matrix barriers to hinder immune cell trafficking, expression of 
non-classical MHC class I, and expression of Fas ligand. (11) The hair follicle has a complex immunologic profile, with immunologically "privileged" matrix cells at its base, and a complement of perifollicular macrophages, mast cells, and other immunocytes that act as the effector arm of the immune system. (9) However; the hair follicles are suspended and hanged inside the dermis; hence; has more surface area that exposed to any surrounding antigen; in addition, the hair follicle has its distinct blood supply. This indicate that there will be more intense inflammatory reaction in the hair follicle in comparison to the adjacent basal layer of epidermis in which only one surface of basal keratinocytes is exposed to dermis. We can speculate that the antigenic stimulation still could be more intense in hair follicles than on epidermis; as the density of various antigens; or receptors could be more numerous in the keratinocytes of outer root sheath than those of epidermis. Hence the immunological and pathological reaction is more florid. Accordingly; all inflammatory skin diseases might start at and will be more intense in the hair follicles than in epidermal cells, and will be presented in a minute macules or papules that coalesce together to form plaques or patches as seen in psoriasis, seborrhic dermatitis and many other diseases . (6,7) The immunological and inflammatory damage might involve the bulb of the hair as in alopecia areata and grey hair vitiligo or involve the shaft of the hair as in LPP and DLE. Similarly; when there is hyperkeratosis of skin, it will be more obvious at the orifices of the hair follicles than the surrounding epidermis as seen in many cases of keratosis pillars. (2) Although the disease start as follicular lesions could be noticeable clinically or microscopically and even could not be observed. The question to be raised why the follicular lesions could not be observed clinically or histopathological? The answer is as follow :the pathology could be so minimal that could not be seen on histopathological section and the the follicular lesion could be transient and then spread to actual epidermis.
The medical literature had neglected the importance of the hair follicle in the disease process hence the present work had definitely confirmed the importance of the hair follicles in the pathogenesis of the diseases. So the present study confirms these observations.

\section{Conclusion}

The present work does encourage us to suggest that almost all skin diseases included in this study start initially on the hair follicle and then spread to involve the adjacent epidermis. Hence lesion start as a follicular that could be noticeable clinically or microscopically, although, sometimes it can't be demonstrated on histopathological section.

\section{Acknowledgment}

We are most grateful for professor Khalifa E. Sharquie as this original idea has been inspired by him.

\section{References}

1. Sharquie KE, Noaimi AA, Mijthab ZM. Chronic scalp folliculitis versus acne vulgaris (observational case series study). J Clin Exp Dermatol Res. 2012; 3(153):2.

2. Thomas M, Khopkar US. Keratosis pilaris revisited: is it more than just a follicular keratosis? Int J Trichol 2012; 4:255-8.

3. Sharquie KE, Noaimi AA, Hameed AF. Lichen Planopilaris is a Common Scarring Alopecia among Iraqi Population. Journal of Cosmetics, Dermatological Sciences and Applications. 2013 Aug 16; 3(3):35-9.

4. Messenger AG, de Berker DA, \& Sinclair RD. Disorders of hair in: Burns T, Breathnach S, Cox N, Griffiths C. Rook's Text Book of Dermatology. 8th ed. UK: Wiley-Blackwell, 2010; 4, 66: 1-11.

5. Erdoğan B. Anatomy and Physiology of Hair. In Hair and Scalp Disorders 2017 May 3. (2):21.

6. Thomas LJ, Dadzie OE, Francis N, Morar N. Follicular Psoriasis-A Forgotten Entity?. Open Dermatology Journal. 2010/4:95-6.

7. Berth-Jones J. Eczema, lichenification, prurigo and erythroderma in: Burns T, Breathnach S, Cox N, Griffiths C. Rook's Text Book of Dermatology. 8th ed. UK: Wiley-Blackwell, 2010; Mar 22/1:1-51.

8. Cotsarelis G, Botchkarev V. Biology of hair follicles. In: Goldsmith LA, Kataz SI, Gilchrest BA, Paller SA, Leffell DJ, Wolf K (eds). Fitzpatrick's Dermatology in General Medicine, 8thed. New 
Adil A. Noaimi et al., AJODRR, 2020 3:28

York, McGrow Hill Company, 2012; 1, 15, 86: compositon and immun privilage. . British Journal 960-8. of Dermatology, 2000/142:862-73.

9. Paus R, Cotsarelis $\mathrm{G}$. The biology of hair follicles. New England journal of medicine. 1999 Aug 12; 341(7):491-7.

11. Paus $R$, Ito $N$, Takigawa $M$. The hair follicle and immune privilege. J Investig Dermatol Symp Proc 2003/8:188-94.

10. Christoph T, Müller-Röver S, Audring H. The human hair follicle immun system: cellular

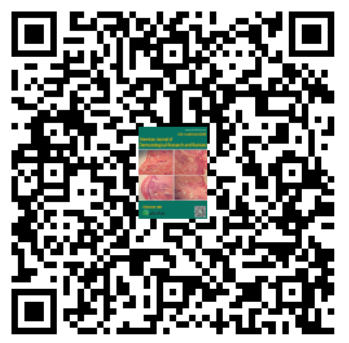

